\title{
REVITALISASI: KAI MURA LE DALAM TRADISI LISAN DOLO THE REVITALIZATION: KAI MURA LE IN THE DOLO ORAL TRADITION
}

Naskah masuk: 4 Februari 2021, direview: 4 Februari 2021, disetujui: 7 April 2021

\author{
Ferdinandus Moses \\ Badan Pengembangan dan Pembinaan Bahasa \\ mosestempo@gmail.com
}

\begin{abstract}
ABSTRAK
Tradisi lisan dolo merupakan tarian massal khas Lamaholot yang sarat akan kelisanan, seperti sole, oha, lili, dan dolo itu sendiri. Penelitian ini berfokus pada dolo di Pulau Adonara, Flores Timur, Nusa Tenggara Timur. Penelitian ini mendeskripsikan interpretasi terhadap teks Kai Mura Le yang digunakan dalam pementasan revitalisasi sastra di Desa Horinara, Adonara. Penelitian ini menggunakan metode kualitatif dengan teknik pengambilan data melalui pengamatan di lapangan, wawancara, dan studi pustaka. Penelitian ini diharapkan menjadi (1) dokumentasi sastra lisan dengan performanya dan (2) memberikan gairah baru atas konsistensi seni tradisi lisan dalam basis komunitas dengan memaksimalkan kekuatan teks sebagai garda depan dalam mengangkat isu-isu keseharian yang berpotensi sebagai sarana kontrol sosial yang berprinsip pada humanitas, holistik, tanggung jawab, dan konstektualitas.
\end{abstract}

Kata kunci: Kai Mura Le, Dolo, Epistemologi, Adonara

ABSTRACT

Dolo's oral tradition is an authentic Lamaholot mass dance that is rich in literacy, as sole, oha, lili, and dolo itself. This research is focused on dolo at Adobara Island, East Flores, East Nusa Tenggara. The research is describing the interpretation on Kai Mura Le, the literature used on literature revitalization stage at Horinara village, Adonara. Qualitative methodology is applied by collecting data from field observation, interview, and literature study. Thus research is expected to be (1) a documentary of oral literature performance, and (2) a rejuvenated passion on oral artistic tradition in community basis by maximizing the literature's power as the frontline in bringing everyday issues that has potential as a social control system which has bumanity, holistic responsibility; and contextually in principle.

Keywords: Kai Mura Le, Dolo, Epistemology, Adonara

\section{PENDAHULUAN}

Dalam KBBI, revitalisasi diartikan sebuah proses menghidupkan atau menggiatkan kembali, maka revitalisasi dalam sastra dapat dikatakan proses ilmu pengetahuan beserta transformasi di dalamnya. Pengetahuan tersebut disebabkan karena sastra memberikan pesan-pesan terbaik bagi kehidupan. Tranformasi di dalam revitalisasi sastra menjadi dominan tatkala sastra lisan yang terancam kepunahannya dihidupkan kembali ke tengah masyarakatnya. Barangkali bagi masyarakat belum punah dan dianggap masih ada. Berujung hal ini hanya menciptakan degenerasi belaka, pada akhirnya menderita stagnansi lantaran matinya regenerasi belaka. Dampaknya, generasi menjadi gagap dan punahnya kepercayaan diri. Pada akhirnya mereka hanya mengetahui bahwa tradisi lisan tersebut sudah berkembang melampaui masa lalu, seperti perubahan syair dolo yang dianggap oleh para generasi lantaran sudah berubah 
ke dalam kemasan lagu-lagu daerah.

Dalam penelitian ini, narasumber di lapangan, Bernard Tukan (63), menggelisahkan para generasi terhadap "pemahaman kelokalan", baginya meskipun transformasi tanpa perubahan adalah sia-sia, tetapi melupakan tradisi lisan sama dengan melumpuhkan keaslian tradisi lisan itu sendiri. Pada akhirnya revitalisasi itu penting; bukan semata pada persoalan tradisi lisan itu sendiri, melainkan kualitas kepercayaan diri, gagasan, pemikiran, serta sudut pandang yang mesti direvitalisasi.

Tidak hanya itu, narasumber Ama Berry (42) dari Dinas Pariwisata Kota Larantuka, mengatakan bahwa dolo sekarang ini lebih diketahui dalam kemasan lagulagu dan bukan pada pola melingkar bergandengan tangan/jari seperti umumnya dahulu dikenal. Begitu pula narasumber di Adonara, David Kopong (63) menambahkan, bila tidak ada kesadaran kolektif dari para guru berbekal bahasa dan sastra, eksistensi dolo dapat tenggelam perlahan-lahan seiring perkembangan zaman. Baginya, para generasi lebih mengenal dentuman musik yang memaksa pada irama untuk bergoyang ketimbang kesenian lokalnya sendiri-apalagi dolo.

Dolo di Kabupaten Flores Timur, Nusa Tenggara Timur merupakan salah satu kebudayaan dari masyarakat Lamaholot. Dolo sudah ada sejak lama, tetapi keberadaanya semakin dilupakan karena pengaruh globalisasi dan modernisasi. Dolo merupakan bagian dari kebudayaan sekaligus cerminan kebudayaan masyarakat Lamaholot. Di dalamnya mencakup sastra lisan yang terkandung pengalaman masyarakat pemiliknya dalam hubungan sosial, pemanfaatan lingkungan, dan penyelesaian konflik (Purwaningsih, 2019).

Demikian penting peran sastra lisan bagi masyarakat pemiliknya, maka secara langsung dolo kembali ditinjau atas perannya bagi masyarakat Lamaholot, terlebih seberapa pentingkah dolo menjadi pandangan hidup sekaligus pengetahuan bagi masyarakatnya sendiri? Sekalipun temuan diperoleh, hal tersebut bukanlah bagi masyarakat setempat saja, melainkan berdampak luas karena pengetahuan yang terkandung sarat resapan moral kehidupan kaya filosofis.

Itulah alasan mengapa tradisi lisan dolo menjadi penting. Dolo merupakan pantun sarat moral kehidupan bermasyarakat. Apapun isu yang diangkat, dolo lebih dari sekadar kebersamaan tradisi Lamaholot di Flores Timur. Setiap ada kebersamaan dalam masyarakat Flores Timur, berarti di situlah dolo hadir. Tradisi tersebut pada hakikatnya sudah bukan lagi keharusan puncak seremonial setiap perjumpaan atau perkumpulan, melainkan etika kehidupan sarat filosofi kalangan tua dan muda. Dalam kesempatan revitalisasi yang sudah dilakukan oleh instansi pemerintah, Badan Pengembangan dan Pembinaan Bahasa, Kemdikbud, adalah kalangan orang berusia muda. Bahkan anakanak dan orang tua sekalipun turut terlibat.

Atas daasar itulah, proses ilmu pengetahuan dalam kemasan revitalisasi terbentuk menjadi medan pembelajaran sekaligus perekatan dalam lintas budaya. Seperti dalam penelitian ini, pantun dalam teks Kai Mura Le dalam tradisi lisan dolo di Adonara, Flores Timur, memiliki keragaman judul yang berbeda. Maksudnya, tematis tradisi lisan yang justru judul cerita menjadikannya berbeda, bila (Flores Timur di Pulau Adonara) tradisi sole dengan semangat pantun yang menceritakan budi jasa nenek moyang dahulu kala, sementara oba dengan pantun yang cenderung sebuah cerita-cerita sedih masa lampau tentang kehidupan nenek moyang. Tradisi sambil berpegangan tangan dalam pantun tersebut divisualisasikan dengan satu gerakan melingkar. Saat itulah mereka menyampaikan ide-ide pokok yang dipantunkan dengan harapan didengar oleh orang di sekitar mulai anak-anak, orang muda, dan orang tua (Klawes, 2019). 
Penelitian ini merupakan asumsi pertanggungjawaban yang dikemas dari program Revitalisasi Sastra Berbasis Komunitas oleh Badan Pengembangan dan Pembinaan Bahasa pada medio 2019 lalu di Nusa Tenggara Timur, tepatnya di Adonara. Tradisi yang direvitalisasi adalah dolo; tarian rakyat massal dalam pola lingkaran. Sebagai tarian massal maka membutukan banyak orang baik laki-laki maupun perempuan. Dahulu, dolo menjadi sarana muda-mudi untuk menjalin cinta melalui lantunan pantun-pantun yang berbalas-balasan yang dibawakan diramaikan dengan pantun-pantun berbalasan, baik yang bernada canda ria dan jenaka maupun nada-nada keriangan lainnya.

Dalam revitalisasi yang bermodelkan pelibatan komunitas, diharapkan menanggalkan ilmu pengetahuan tersendiri dalam intensitas dolo terus bergerak bersama pemangku kepentingan sekitar, seperti Dinas Kebudayaan dan Pariwisata dan tetua adat kampung setempat, maupun para cendekia/seniman tradisi dalam pendekatannya bagi masyarakat. Sebuah pendekatan yang diharapkan meski sudah menjadi media pembelajaran dalam muatan lokal sehingga nilai-nilai moral menyatu bersama pelajar juga pendidik. Penelitian ini diharapkan berkembang bagi masyarakat dengan segala muatan pembelajaran di dalamnya. Penelitian yang berfokus pada dolo ini, semoga memberikan sumbangsih tersendiri bagi situasi peradaban yang semakin bertumbuh.

Selain perkembangan bagi masyarakat dengan pemangku kepentingan di dalamnya, penelitian ini bersumber pada tafsiran atas teks Kai Mura Le. Teks tersebut merupakan bagian rekam-jejak dari puncak revitalisasi yang sudah dilaksanakan. Prinsip humanitas, holistik, tanggung jawab, dan kontekstualitas pada akhirnya semoga dapat merincikan tentang bagaimana tradisi lisan dolo dapat menjadi penting.

Pemikiran atas empat prinsip di atas berangkat dari filosofi ilmu pengetahuan, yakni teori epistemologi. Epistemologi memberikan tekanan pada proses ilmu pengetahuan bekerja-bagian dari kerangka berpikir filsafat, di antara ontologi dan aksiologi. Terminologi pemikiran tersebut atas ontologi yang membahas perihal keinginan untuk diketahui mengenai teori tentang "ada“. Istilah lain, yakni bagaimana hakikat objek yang ditelaah sehingga membuahkan pengetahuan. Epistemologi membahas tentang bagaimana proses memperoleh pengetahuan dan aksiologi membahas nilai yang berkaitan dengan kegunaan atas pengetahuan yang diperoleh (Suriasumantri, 1990:33).

Pendekatan secara langsung akan membuktikan bahwa kesungguhan dolo adalah ilmu pengetahuan bagi masyarakat Lamaholot. Dalam konteks penelitian ini adalah teks Dolo Kai Mura Le. Filosofi tersirat yang bertanggung jawab terhadap keempat prinsip seperti sudah disebutkan. Penelitian ini secara khusus berfokus pada teks Kai Mura Le dalam tradisi lisan dolo. Secara langsung Kai Mura Le diartikan sebagai dolo yang sudah banyak/ramai pesertanya (secara lisan dinyanyikan dolo Kai Mura Le).

Penelitian ini didekatkan atas prinsip humanitas, holistik, tanggung jawab, dan konstekstualitas. Pendekatan dianggap penting mengingat cakupan dalam revitalisasi sastra, merupakan prinsip mendasar dalam eksistensi kebertahanannya.

Pendekatan atas keempat prinsip tersebut berpijak dari Watloly (2007: 183-227) dalam catatan Jannes Alexander Uhi 'Pengembangan Epistemologi dalam PrinsipPrinsip Kultural', yakni kehadiran prinsip humanitas yang menekankan bahwa manusia mempunyai kedudukan sentral dalam rangka pengembangan sebuah ilmu-dalam konteks revitalisasi. Tambahan dari catatan tersebut, prinsip ini menegaskan bahwa pengetahuan merupakan realisasi kemampuan-kemampuan kodrat manusia melalui rasio, dan realisasi epistemologinya harus selalu bersifat proses belajar (learning process). 
Prinsip kedua, yakni prinsip holistik. Pengembangan epistemologi yang berwawasan holistik mengandung pengertian bahwa kebenaran pengetahuan selalu bersifat intersubjektif. Pengetahuan, dalam hal ini, bukan hanya bersifat mengalami, tetapi mengekspresikan pengalaman sendiri bagi dirinya sendiri.

Prinsip ketiga, yakni prinsip tanggung jawab. Watloly (2007:208) dalam Jannes Alexander Uhi menyebutkan, tanggung jawab ilmuwan juga memiliki arti mendudukkan manusia pada kedudukannya di antara manusia-manusia lain. Pernyataan Watloly dalam Jannes Alexander Uhi ini menegaskan bahwa tanggung jawab selalu menjadi keharusan dari setiap permasalahan yang timbul atas perkataan ataupun perbuatan yang dilakukan oleh seseorang. Prinsip tanggung jawab dengan sendirinya mengandung unsur humanis yang dalam. Alasannya, setiap ilmu dan pengetahuan yang dihasilkan oleh manusia selalu bersumber dari semua hal yang nyata di sekitarnya.

Prinsip keempat, yakni prinsip kontekstualisasi. Menurut Jannes Alexander Uhi, bahwa kondisi budaya masyarakat dapat memberikan dorongan atau pengaruh bagi pengembangan epistemologi. Artinya, epistemologi menyatu dengan seluruh struktur sosial dan tradisi kebudayaan.

Keempat prinsip, seperti disebutkan di atas, berangkat dari bentuk pemikiran epistemologi. Sebuah bentuk dari pereduksian epistemologi yang diharapkan dapat mempertimbangkan prinsip-prinsip kultural dalam suatu masyarakat. Pereduksian epistemologi bermaksud untuk mengembangkan epistemologi yang ada menjadi epistemologi yang realistis. Realistis epistemologi yang dilakukan untuk mempertimbangkan faktor budaya masyarakat di dalamnya.

\section{METODE PENELITIAN}

Penelitian ini merupakan penelitian literaratur dari kegiatan sastra lisan di lapangan. Penelitian dilakukan terhadap karya tertulis, yakni teks Dolo Kara Mura Le, pemikiran tokoh yang telah maupun belum dipublikasikan, dan wawancara.

Metode yang digunakan dalam penelitian ini ialah metode kualitatif. Hasil penelitian ini diharapkan menjadi (1) dokumentasi materi sastra lisan sekaligus performanya dan (2) memberikan temuan baru dalam situasi sastra lisan yang secara langsung mendapatkan teks sastra sekaligus tafsirannya.

\section{PEMBAHASAN}

\subsection{Sastra Lisan Dolo}

Dolo merupakan tarian persatuan bagi masyarakat Flores Timur, Lembata, Adonara, Solor, dan Alor. Tarian ini dikategorikan sebagai tarian massal yang dapat diikuti oleh semua masyarakat dari berbagai kalangan. Namun, dolo sangat menonjol bagi muda-mudi sebagai arena perjumpaan untuk membangun persahabatan dan juga ajang untuk menemukan jodoh dan menjalin cinta dua sejoli.

Kata dolo yang dikenal selama ini, menurut narasumber di lapangan, David (63), bermula dari kata dola, yakni paduan nada do dan la sebagai standar bunyi atau nada awal dalam penyampaian syair atau pantun. Kemunculan pelantun nada awal ini, dalam praktiknya, disambut oleh pelantun pantun lainnya. Secara langsung dianggap dijadikan pegangan standar dalam refrein dan berbalas pantun.

Masyarakat Flores pada umumnya, khususnya Flores Timur, menjunjung tinggi nenek moyang atau leluhur yang pada prinsipnya adalah mediator dalam hubungan manusia dengan Tuhan. Begitu pula terhadap asal-usul silsilah kehidupan yang sarat keterkaitan. Karena itu, masyarakat pun meyakini bahwa mereka terdiri atas beberapa suku, yakni suku asli yang berasal dari suku Ile yang lahir dari Gunung Ile Mandiri 
dengan leluhurnya Wato Wele dan Lia Nurat. Namun diyakini juga bahwa saat suku ini lahir, sudah ada juga suku Paji yang dianggap merupakan keturunan dari manusia gaib (mata mere). Keturunan Ile Jadi ini nantinya akan menjadi suku Demon yang menjadi lawan suku Paji.

Suku imigran pertama di Flores Timur adalah suku Tena Mau, yaitu pendatang yang berasal dari Indonesia bagian Timur yang terdampar akibat perahu (tena) mereka terdampar (mau). Termasuk di dalamnya orang-orang Kroko Puken dan orang-orang Seram Goran. Kroko Puken dianggap berasal dari Pulau Lapan Batang di daerah Kabupaten Lembata, sebuah pulau yang ke bawah laut. Pulau itu terletak di antara Pulau Adonara dan Lembata. Kedua, suku tersebut berasal dari Sina Jawa 'Suku Jawa' yang berasal dari Indonesia bagian Barat. Suku Sina Jawa ini dipercaya merupakan para pelaut dari Kerajaan Majapahit yang berlayar ke arah timur (Lawe, 2018).

Silsilah sejarah ini selalu diceritakan secara turun-temurun dari orang tua ke anak, anak ke cucu, dan seterusnya. Hal ini menjadi sastra lisan dengan tingkat mutu yang sangat tinggi. Biasanya sastra tutur ini disampaikan dalam berbagai bentuk puisi, pantun, syair, nyanyian-nyanyian pantun, ataupun legenda.

Cerita sejarah suku-suku tersebut juga diceritakan dalam acara puncak dalam dolo yang disebut soleb ketika acara dolo muda-mudi selesai berpantun. Soleh tersebut mengungkapkan sejarah, ucapan syukur, kesedihan, kepahitan hidup, dan doa kepada Tuhan yang Mahakuasa. Dolo merupakan perkembangan dari tarian banama pada zaman dulu. Dolo dikemas sebagai tarian untuk ucapan rasa syukur masyarakat Flores Timur, khususnya Lamaholot atas panen hasil bumi di tanah mereka. Seiring waktu berjalan, di masa-masa modernisasi tarian banama ini pun lenyap dan tergantikan dengan tarian dolo hingga saat ini.

Perlu dijelaskan, tarian dolo memiliki kekkhasan pada gerakan kaki yang melangkah dalam bentuk aturan dua ke depan, dua ke belakang, dan dua ke samping. Gerakan tersebut mesti sinkron dengan ketukan dolo yang berirama 2/4. Alat musik dalam dolo biasanya diiringi oleh gendang atau gong. Setakat itu, kebanyakan orang menggunakan alat musik lain seperti gitar, biola, ukulele, bas, dan gendang sebagai alat musik utamanya dan penentu ketukan atau penanda irama.

Kata-kata dalam syair dolo secara tersirat melambangkan nilai-nilai persahabatan dan dimanfaatkan oleh muda-mudi untuk mencari pasangan. Tarian dengan syair itu biasanya dimainkan dalam tarian dolo dalam sebuah pesta pernikahan pada suku Lamaholot, pada acara syukuran, pada musim panen, dan kegiatan masyarakat lainnya; dengan tarian berbentuk lingkaran besar dan jari kelingking saling berkaitan di antara penari. Tarian ini berakhir jika sudah tidak ada lagi peserta tari yang bisa membalas pantun yang dinyanyikan oleh peserta lainnya.

Pada prinsipnya, selama masih bisa berbalas-balas pantun maka tarian ini tidak akan pernah berakhir. Segala hal dirayakan secara bersama-sama. Kegembiraan, syukur, kesedihan, kepahitan hidup, pernikahan dan seterusnya. Puncak tertinggi dari ritual adat adalah perayaan bersama, doa bersama yang hampir selalu diwujudkan dalam bentuk dolo. Hal ini juga yang melahirkan cara ungkapan dengan bergandengan tangan sambil melingkar dan disebut dolo. Dolo yang berkembang dari tarian yang lebih tua disebut banama: tarian yang dipentaskan sebagai rasa syukur. Tarian ini semakin punah setelah semangat dan ritmenya bertransformasi ke dalam tarian dolo. Karena dalam tarian dolo gerakan kaki yang melangkah dalam bentuk langkah dua-dua (dua ke depan, dua ke belakang, dua ke samping), gerakan kaki yang lincah ini menghasilkan syncope pada ketukan sehingga musik dolo selalu berirama 2/4 (Klawes, 2019).

Menurut narasumber di lapangan, dolo dapat diiringi gendang atau gong. Pada 
keadaan lain orang sering menggunakan alat musik lain seperti gitar, biola, ukulele, bas dengan gendang adalah alat musik utamanya dan penentu ketukan atau penanda irama. Ada berbagai bentuk pukulan untuk dolo yang makin lama makin berkembang sesuai eksplorasi dan kreativitas pemusik yang juga berkembang. Semua bentuk pukulan selalu berpatokan pada pukulan dasar berikut (2/4) //X.X/X.X/X.X// jika menggunakan satu gendang, atau ditambah dengan (2/4)//Xxx.X/Xxx.X/Xxx.X// jika gendang kedua, atau ditambah dengan (2/4)//X./X X/X./XX// jika menggunakan gendang ketiga. Biasanya ketiganya digabungkan, atau dimainkan salah satunya, atau kolaborasi dua-dua.

Pada saat ini, Flores Timur, cukup dibilang sulit menelusuri tangga nada asli yang dipakai dalam dolo, karena akulturasi budaya secara tersirat menyebabkan tangga nada yang dipakai selalu diatonis. Namun, ada kekhususan di sini. Dalam bentuk yang lebih tua, nada finalisnya adalah 3 (mi,E), seperti bentuk tangga nada frigis dalam musik gregrorian. Nada finalis 1 (do,C) baru ada dalam bentuk yang lebih modern (Klawes, 2019). Maka, dolo menjadi khas lantaran "estetika pelafalan" yang menjadikan dolo sangat indah dan berkarakter. Pelafalan terutama terjadi di akhir kalimat syair, atau ketika ada not yang dimainkan secara berulang.

Dolo dalam konteks penelitian ini secara tersirat melambangkan nilai-nilai persahabatan dan seringkali dimanfaatkan oleh kaum muda untuk mencari pasangan. Biasanya dimainkan oleh para generasi muda pada waktu-waktu tertentu, misalnya acara syukuran, pada malam bulan purnama. Dalam dolo ini (siapa saja boleh mengikuti) akan saling menautkan jari kelingking dan membentuk lingkaran. Jika peserta banyak, lingkaran bisa terdiri dari tiga lapis atau lebih. Para peserta akan saling melantunkan pantun dan saling berbalasan. Dolo akan berakhir jika sudah tidak ada lagi peserta yang bisa membalas pantun yang dinyanyikan oleh peserta lainya. Selama masih bisa berbalas-balas, tarian ini tidak akan berakhir.

Tarian dolo biasanya dibawakan dengan nyanyian dolo. Zaman dulu dipentaskan pada puncak tertinggi dari ritual adat yakni perayaan bersama, doa bersama, yang hampir selalu diwujudkan dalam bentuk tandak atau tarian dolo. Tarian ini melambangkan nilai-nilai persahabatan dan seringkali dimanfaatkan oleh kaum muda untuk mencari pasangan (jodoh). Tarian ini biasanya dimainkan oleh para generasi muda pada malam bulan purnama. Dalam tarian ini (siapa saja boleh ikut serta) akan saling menautkan jari kelingking dan membentuk lingkaran.

\subsection{Teks Kai Mura Le dalam Tradisi Lisan Dolo}

Teks Kai Mura Le dalm tradisi lisan dolo merupakan teks yang berangkat dari proses pembelajaran bagi sebuah komunitas untuk terus menghidupkan dolo. Maksudnya, proses menjadi teks ini adalah bagian atas generasi muda di Adonara bagi harapan keberlangsungan dolo agar terus hidup dan tidak terlupakan. Teks bergantung isu tema seputar remaja, sehubungan dengan proses revitalisasi bagi para generasi dalam basis komunitas. Maka atas asumsi penelitian ini, dampak dirasakan akan lebih memiliki bobot bila dapat dipertanggungjawabkan bagi masyarakatnya; bahwa tradisi bukanlah sesuatu yang tiba-tiba saja datang lantas pergi, melainkan menanggalkan pemikiran untuk bisa diperhitungkan. Kali ini diperhitungkan dalam kekuatas teks tersebut, semangat epistemologi kian penting karena secara tersurat menampakan prinsip humanitas, holistik, tanggung jawab, dan kontekstualisasi.

Berikut teks Dolo Kai Mura Le disertai arti dan pembahasannya.

Pandang tobo, pandang tobo, mayang bera dai pandang tobo Koli bako, bako bera wati mayang dai 
dai pandang tobo.

(Demi rasa hormatku, aku panggil kamu duduk di sini. sekalipun koli dan tembakau belum tersedia)

Kala tukang-kala tukang, go pithing kotor, kotor kala tukan

Di sekophang, sekophang neking wanang, go pithing kotor, kotor kala tukang.

(Merasa bangga aku yang hinda-dina ini duduk diapit dua gadis jelita)

Gawe gere-gawe gere, ake soot, soot gawe gere Opum anang reum ata nimung, ake soot, soot gawe gere.

(Janganlah takut melangkah masuk, di rumah si gadis anak pamanmu, janganlah takut melangkah masuk)

Etep teti belia lidang, cuma kabe, kabe lidang saja Cuma kabe, kabe lidang saja, lidang kete keteko di hala.

(Aku ajak kamu, marilah duduk berdampingan bersamaku, dengan berdampingan kamu tidak akan aku bawa pergi

W ai rae nora sareng, ke tada sareng mooro tobo Tade sareng, sareng mo'oro tobo, go medhong kurang, kurang onek hala.

(Dia yang terbaik dan cocok menjadi pilihanmu, karena aku yang dina ini tidak kurang hati)

Pana pai haka nai, wuge bera mo pana pai Wuge tuen, tuan sora timor, wuge bera, bera pana pai. (Segeralah menyanggul rambutmu dan cepatlah datang kemari)

Bera baing, bera baing niding ake, ake bara baing kaang berhang, berhang koi hala niding ake, akee bera baing.

(Janganlah memintaku bergegas, karena aku tak biasa terburu-buru)

Hope dimung Kupang dai, hope sasing, sasing ra keropong

Sedon sagu, sagu Adonara, naraneng data di bebelelng kae.

(Sedo yang selalu memberikan si pemuda ole-ole ternyata sudah rusak tabiatnya sejak lama)

Ile ikit woka soga, Cuma soga, soga naran saja

Wai lai salang data, go dathak doro-doro doan hala.

(Sekalipun rusak air dari pancurannya, rusak sikapku tidak separah perkiraanmu)

Lau pai baka kai, belo bunga-bunga baruan rua

Belo bunga-bunga baran rua

Kete tou genang tou.

(Ada dua cabang bunga muda (gadis remaja), kupilih satu kubawa pergi, entahlah satunya)

Mete tou-mete tou, tada bote, bote moen tou

Burong bur'ang, bur'ang rua

Pasang, tada bote, bote mete tou. 
(Ada dua gadis kembar ibarat merpati, pilihlah seorang jadi milikmu)

Teti Ambon ro Menado, maring wati mplo nadon

Doang Kupang-Kupang Surabaya, baya hala, hala mede miang

Artinya, Hei kau gadis, belum ada kata kuucapkan

(Tetapi kamu telah mengangguk, tak pernah kita berjanji tetapi kamu menggangguku?)

Wuno pito ile lolong, pithing bunghang-bunghang bahe kae

Pari lema-lema lolong gadak, ago badan nele hala kae.

(Mataharimu menuju senja, maka berdandan serupa apapun, sudah pudarlah kepantasannya)

Lusi lie lere lere, beka epang kayo nadang bala, beka epang kayo nadang bala, Kopong bas 'bako naku bal 'ham take.

(Ketika duduk bercanda ria, kopong lancang mencubit-cubit, padahal tidak punya gading sebatang pun)

Bera marin-bera maring, geniko hae, hae bera maring

Geniko hae, hae bera maring, go kai seba kala goeng gehak.

(Katakanlah segera, jika kamu menolak lamaranku, supaya aku mencari saja yang lain)

Teti pedang barang tawa, tawa koono di hama hala

Wua mapak malu koleng, kiang kolenek di esi mure.

(Kamu boleh melamarku, tapi karena umur kita tidak seimbang biarlah aku menikmati kesendirian sesaat lagi)

Ra kebarek bala weling, weling-weling go peweli rehik

Ra kebarek, kebarek Witihama, ti tite-tede, tide hama hena.

(Para gadis bermaharkan gading, jika berjumlah banyak, tak mampulah aku)

Gampang hala, gampang hala ata ana, ana gampang hala ana weling, weling witi bala, ata ana, ana gampang hala.

(Sungguh tidak mudah mengambil anak gadis itu, karena dia bermaharkan gading dan kambing)

Petung rae tede tenang, tenang arik mo geninang onem Au weli, weli orang gowa, arik ake gowa wekim kire.

Artinya, jagalah hatimu dengan baik adikku, janganlah membanggakan hatimu dulu

Kede kiang, kede kiang, lelana hae, hae kede kiang

Ruat baya taro mateng kae, lelana hae, bae kede kiang.

(Sekalipun lama, saya akan tetap menunggu, karena kesepakatan kita sudah pasti)

Tobi teti lolong tueng, sedo mabe-mabe tueng onem

Tobi teti lolong tueng, sedo mabe-mabe tueng onem

Bao lali, lali wung balik, ke balik ata, ata barang goek.

(jika kamu, Sedo berbalik ke lain hati,

kembalikan semua barang pemberianku) 
Tobi tobang tika wiking, bao biki, biki bage ratang

Ruat tabe-tabe bage rarang, ti moem teti, teti goek lali.

(Kita duduk berdampingan bercanda ria

Memadu kasih, kita dua berbagi jalan, engkau di sana, aku di sini)

Dibeuto ile aleng ke

Hoking pekeng-pekeng hoking peken

Hoking pekeng, pekeng hoking peken,

Go boking purek, pu rek pago kete.

(Telah kami lakukan hal terlarang dengan seorang gadis, tapi karena saya orang terakhir, biarlah dia aku bawa)

Teti tuwo buko lodo, tuwo pureko di kae nire

Lali wato tena bera

Maaro berara di kae nire

(Jangan lagi disesali lagi karena semuanya telah terlambat, kamu telah telanjur melakukannya)

Doan Lite Lama ole, doang denge ole lolong kae

Doang denge ole lolong kae

Go lesu leik-leik lorang limak.

(Mendengar beritamu

Telah jauh berlayar

Lesulah kaki dan tanganku)

Tapo tani-tapo tani

Tobo tonga-tonga tapo tani

Kiden kala-kala ina wae

Go tobo tonga, tonga tapo tani

Artinya, ketika lapar kutengadahi kelapa muda

Lantaran aku perempuan sebatang kara

(tidak dapat memanjat)

Mete tani-mete tani, bayang tena, tena mete tani

Susah niki-niki wai take

Go bayang tena, tena mete tani.

(Aku dayung perahu sambil menangis

Karena tidak ada bekal yang aku punyai)

Tabe aku, tabe aku

Tai maring, maring tabe aku

Teti nabe, nabe sera sorong

Ke tai maring, maring tabe aku.

(apa yang mesti kita keluhkan karena nasib hidup kita

adalah penyelenggaraan-Nya)

Aerunta Wulang haka lega lewo

Mo kepae-kepae nenang goek

Revitalisasi: Kai Mura le dalam Tradisi ...(Ferdinandus Moses) 
Mo kepae-kepae nenang goek, nenang ake, akene lupa lela.

(Biarpun bulan berganti bulan, jangan kiranya kamu melupakan janji di antara kita berdua)

Watan haka-watan haka, lering dore dore watan haka

Guti rata, rata taping tena, tena tueng, tueng balik bala.

(berjalan menyusuri tepi pantai, sambil mendambakan engkau

yang tak kunjung datang)

Prinsip humanitas berdasarakan teks Kai Mura Le adalah pengetahuan atas realisasi kemampuan-kemampuan kodrat manusia melalui rasio dan realisasi epistemologi yang bersifat proses belajar (learning process). Hal tersebut tampak pada Gawe gere-gawe gere, ake soot, soot gawe gere Opum anang reum ata nimung, ake soot, soot gawe gere 'janganlah takut melangkah masuk, di rumah si gadis anak pamanmu, janganlah takut melangkah masuk'. Penegasan tampak bagi prinsip kehidupan. Sebuah pengetahuan yang diumpamakan ke dalam amanat sekaligus amanah, bahwa bila sudah disertakan/ besertakan kejelasan tujuan, tidak perlu lagi dikendalikan oleh keragu-raguan.

Kemudian dalam teks Mete tou-mete tou, tada bote, bote moen tou, burong bur'ang, bur'ang rua pasang, tada bote, bote mete tou 'ada dua gadis kembar ibarat merpati, pilihlah seorang jadi milikmu' memberikan pelajaran bahwa ketika berhadapan dengan dua pilihan dalam hidup, maka harus ada satu untuk dipilih. Suatu perilaku normal sebentuk pengajaran bahwa tidak untuk memilih semua diinginkan dalam memilih, tapi ada satu mesti diputuskan—suatu prinsip yang ditanamkan bagi generasi sejak dini untuk tidak berperilaku "serakah" dalam kehidupan.

Teks Kala tukang-kala tukang, go pithing kotor, kotor kala tukan Di sekophang, sekophang neking wanang, go pithing kotor, kotor kala tukang, 'merasa bangga saya yang dina duduk diapit dua gadis jelita' merupakan proses belajar masyarakat Lamaholot dalam meresapi eksistensi rasa keyakinan atau kepercayaan diri, ada hal perlu diapresiasi bagi dirinya-bahwa meski mengalami kekurangan, tetapi bukan berarti lingkungan sekitar turut menjauhinya, melainkan sebaliknya.

Bera marin-bera maring, geniko hae, hae bera maring. Geniko hae, hae bera maring, go kai seba kala goeng gehak, katakanlah segera, jika kamu menolak lamaranku, supaya aku mencari saja yang lain' secara tersirat menunjukkan perasionalan atas diri sendiri lantaran situasi lingkungan (dalam hal ini konteks "penolakan asmara"). Sebuah sikap optimis dan tanpa pamrih terhadap lingkungan. Hal ini secara langsung juga menunjukkan sikap humanis bagi individu terhadap individu lainnya.

Wai rae nora sareng, ke tada sareng mooro tobo Tade sareng, sareng mo'oro tobo, go medhong kurang, kurang onek hala 'dia yang terbaik dan cocok menjadi pilihanmu, karena saya yang dina tak kurang hati' merupakan sikap humanis terhadap lingkungan dalam situasi sarat keberterimaan. Teks berikutnya Lau pai haka kai, belo bunga-bunga baruan rua Belo bunga-bunga baran rua Kete tou genang tou 'ada dua cabang bunga muda (gadis remaja), kupilih satu kubawa pergi, entahlah satunya', asumsi teks tersebut atas prinsip humanitas, yakni perasionalan kehidupan untuk memutuskan. Pada akhirnya adalah sebuah keputusan yang baik menentukan kualitas individu yang humanis.

Teks Teti Ambon ro Menado, maring wati mplo nadon Doang Kupang-Kupang Surabaya, baya hala, hala mede miang 'hei kepada kau gadis, belum ada kata aku ucapkan, tetapi kamu telah mengangguk, tidak pernah kita berjanji tetapi kamu menggangguku?'teks yang merupakan kejelasan atas situasi humanis, mempertanyakan kembali terhadap prinsip rasional dalam berkehidupan bahwa tidak ada sebab bila tidak ada 
akibat. Hal ini menunjukkan prinsip humanis untuk selalu kritis. Mempertanyakan hal -hal yang dirasakan kurang atau tidak adanya kelogisan akal sehat/pemikiran.

Pada Teks Lusi lie lere lere, beka epang kayo nadang bala, beka epang kayo nadang bala, Kopong bas 'bako naku bal 'ham take 'ketika duduk bercanda ria, kopong lancang mencubit-cubit, padahal tidak punya gading sebatang pun', merupakan suatu sikap spontan serta menyimpan maksud keterus-terangan sekaligus kejujuran dari sikap individu. Secara tidak langsung, hal itu suatu kodrat manusia yang pada dasar kenormalannya tidak ingin menyakiti sesama manusia lainnya. Selain itu, juga terdapat sikap kepercayaan diri seorang lelaki.

Teks Tobi tobang tika wiking, bao biki, biki bage ratang Ruat tabe-tabe bage rarang, ti moem teti, teti goek lali kita duduk berdampingan bercanda ria memadu kasih, kita dua berbagi jalan, engkau di sana, aku di sini' menonjolkan prinsip kebersamaan menuju proses pembelajaran bersama. Dalam Dolo Kai Mura Le, ketika bergandengan tangan satu dengan lainnya, berdua bukanlah berarti seperti halnya sepasang kekasih, melainkan juga sepasang kelompok atau dua kelompok untuk saling berbagi jalan; bertukar pikiran juga ide. Sebuah prinsip yang berkesan "filosofis dan sarat makna". Konteks dua kelompok di sini juga mengartikan dua kampung, dua keluarga, bahkan dua wilayah.

Teks Dibeuto ile aleng ke Hoking pekeng-pekeng hoking peken Hoking pekeng, pekeng boking peken, Go hoking purek, pu rek pago kete 'telah kami lakukan hal "terlarang" dengan seorang gadis, tapi karena saya orang terakhir, biarlah dia aku bawa' menekankan pembelajaran dalam bersikap bertanggung jawab. "Terlarang" di sini berkonteks seperti hal yang tidak diperbolehkan oleh orangtua karena berlainan kampung atau asal-usul, tetapi tetap belajar untuk bersikap bertanggung jawab atas situasi keterlanjuran yang sudah saling "jatuh cinta".

Prinsip holistik dalam teks Kai Mura Le. Pengembangan epistemologi atas bangunan pengertian bahwa kebenaran bersifat intersubjektif-dalam hal ini, bukan hanya bersifat mengalami, melainkan mengekspresikan pengalaman bagi dirinya sendiri. Dalam Kai Mura Le, kebenaran yang dianggap/sebentuk pengakuan eksistensi diri lewat syair ialah para pendolo yang menciptakan kenyataannya sendiri. Hal tersebut tampak pada Ile ikit woka soga, Cuma soga, soga naran saja, Wai lai salang data, go dathak doro-doro doan hala 'sekalipun rusak air dari pancurannya, rusak sikapku tak separah perkiraanmu'. Asumsi atas prinsip holistik memberikan pembelajaran tersendiri, yaitu tentang bangunan sikap atau prinsip hidup yang berpegang teguh terhadap pegangan kebenarannya sendiri, selagi ekspresi tersebut mengajak supaya tidak mengadili kehidupan ini atas azas keburukan praduga. Sejatinya tidak dibenarkan memandang kehidupan ini dengan sikap setengah hati, tapi harus penuh dalam kepercayaan diri.

Wuno pito ile lolong, pithing bunghang-bunghang bahe kae Pari lema-lema lolong gadak, ago badan nele hala kae 'mataharimu menuju senja, maka berdandan serupa apapun, sudah pudarlah kepantasannya' merupakan analogi perumpamaan tentang matahari, sekalipun menampilkan keindahan seperti senja, pada akhirnya terbenam/tenggelam juga. Sebuah prinsip bahwa dalam kehidupan ini tidak ada yang pantas untuk dibanggakan berlebihan. Termasuk pembelajaran tentang hidup mestilah apa adanya kodrat yang sudah dilahirkan; bila memaksakan kehendak melebihi tampilan, kelak akan sirna juga. Demikian proses pembelajaran atas teks tersebut dalam dolo.

Bera baing, bera baing niding ake, ake bara baing kaang berhang, berhang koi hala niding ake, ake bera baing 'janganlah memintaku bergegas, karena aku tak biasa terburu-buru' merupakan prinsip untuk tidak memaksakan kehendak. Terlebih tidak perlu untuk melakukan segala aktivitas kehidupan ini dilakukan penuh ketergesaan tanpa 
ketenangan.

Teks Gampang hala, gampang hala ata ana, ana gampang hala $\mathrm{R} a$ kebarek bala weling, weling-weling go peweli rehik Ra kebarek, kebarek. Witibama, ti tite-tede, tide hama hena 'para gadis bermaharkan gading, jika berjumlah banyak, tak mampulah aku' merupakan pengalaman atas tradisi adat bahwa untuk meminang seorang gadis dilakukan dengan gading. Bila hal tersebut tidak dapat dilakukan, maka mesti berlapang dada menerima segala kemungkinan yang akan terjadi-prinsip dalam diri sendiri untuk bersikap menerima setiap keputusan dalam berkehidupan. Hal tersebut mengindikasikan keberbagian atas pengalaman individu yang dituangkan ke dalam dolo agar menjadi perenungan sekaligus prinsip bersama.

Teks Doan Lite Lama ole, doang denge ole lolong kae Doang denge ole lolong kae Go lesu leik-leik lorang limak 'mendengar beritamu telah jauh berlayar lesulah kaki dan tanganku' sebuah perumpamaan atas prinsip pengalaman dari individu, bahwa kelak hal itu tidak perlu dilakukan sebab dapat menguras tenaga dan air mata. Melalui dolo diharapkan tetap timbul keriangan lantaran dilakukan bersama-sama. Bersama bergandengan tangan untuk memberi pembelajaran dari masing-masing pengalaman.

Teks Tapo tani-tapo tani Tobo tonga-tonga tapo tani Kiden kala-kala ina wae Go tobo tonga, tonga tapo tani ketika lapar aku tengadahi kelapa muda lantaran aku perempuan sebatang kara (tidak dapat memanjat)' sebuah keberbagian pembelajaran yang berangkat dari pengalaman individu untuk direnungi bersama-sama. Hal tersebut merupakan pembelajaran agar seorang perempuan, meski tidak dapat melakukan hal biasa dilakukan oleh laki-laki (memanjat) tetap bersabar. Kesabaran dengan tidak melawan kodrat, sekaligus kesabaran menunggu (menengadahi) kelapa. Sebuah prinsip kesabaran dan kelak akan ada laki-laki yang memanjat untuk membantunya.

Berikutnya, prinsip tanggung jawab dalam teks Kai Mura Le bahwa manusia pada kedudukannya di antara manusia-manusia lain. Penegasan atau sikap yang selalu keharusan dari setiap permasalahan atas perkataan ataupun perbuatan dari seseorang. Secara langsung mengandung reduksi kedalaman situasi kemanusiaan yang tidak dangkal. Alasan tersebut atas asumsi bahwa setiap ilmu dan pengetahuan yang dihasilkan oleh manusia selalu bersumber dari lingkungan sekitar. Hal tersebut tampak pada Petung rae tede tenang, tenang arik mo geninang onem, Au weli, weli orang gowa, arik ake gowa wekim kire 'jagalah hatimu dengan baik adikku, janganlah membanggakan hatimu dulu'. Sebuah prinsip yang secara tidak langsung memberikan pelajaran tentang tanggung jawab dalam kehidupan untuk senantiasa memiliki kerendahan hati. Hal terpenting lagi atas prinsip kehidupan ini bahwa tidak ada keaslian dalam kehidupan ini, di atas kehidupan ada kehidupan yang lain, dan terpenting supaya lelaku kehidupan ini tidak dikendalikan oleh nafsu belaka, tetapi harus bisa menahan diri. Syukur dapat melayani orang lain terlebih dahulu sebelum sibuk melayani diri sendiri.

Teks Pandang tobo, pandang tobo, mayang bera dai pandang tobo Koli bako,bako bera wati mayang dai dai pandang tobo 'demi rasa hormatku kupanggil kamu duduk di sini. sekalipun koli dan tembakau belum tersedia' mengejawantahkan sikap bertanggung jawab atas panggilan untuk duduk bersama. Sebuah prinsip filosofis bahwa kebersamaan lebih diutamakan. Hal tersebut mencerminkan sikap saling menghargai. Penghargaan yang tidak boleh dipandang dari materi semata, tapi lebih pada situasi kemanusiaan untuk saling menghormati.

Teks Pana pai haka nai, wnge bera mo pana pai Wuge tuen, tuan sora timor, wnge bera, bera pana pai 'segeralah menyanggul rambutmu dan cepatlah kemari' merupakan sikap bertanggung jawab untuk bersikap rapi. Kerapihan tulus dilakukan tanpa dandan berlebihan, tapi cukup dengan merapikan rambut. Prinsip tanggung jawab yang 
sederhana.

Teks Teti pedang barang tawa, tawa koono di hama hala Wua mapak malu koleng, kiang kolenek di esi mure 'kamu boleh melamarku, namun karena umur kita tidak seimbang biarlah aku nikmati kesendirian sesaat lagi' mencerminkan prinsip pembelajaran untuk bertanggung jawab terhadap diri sendiri menuju kebaikan bersama. Tanggung jawab yang mesti disadari sekaligus dilakukan oleh pemuda untuk menyadari usia yang tepat dalam berkeputusan. Pada akhirnya usia memberikan gambaran tentang pemodelan bertanggung jawab melalui usia. Sebuah pembelajaran yang bersifat bagi manusia untuk melihat konteks kehidupan melalui usia.

Pada teks Kede kiang, kede kiang, lelana hae, hae kede kiang Ruat baya taro mateng kae, lelana hae, hae kede kiang 'sekalipun lama, saya akan tetap menunggu, karena kesepakatan kita sudah pasti' merupakan prinsip bertanggung jawab yang mesti ditumbuhkan dalam mental. Sifat yang cenderung tergesa dalam keputusan, mesti memunyai sikap penuh kesabaran.

Teks Mete tani-mete tani, bayang tena, tena mete tani Susab niki-niki wai take go bayang tena, tena mete tani kudayung perahu sambil menangis karena tidak ada bekal yang aku punyai' merupakan prinsip bertanggung jawab terhadap diri sendiri. Hal tersebut diasumsikan atas metafora frasa mendayung perahu adalah tetap melaju dalam kehidupan. Hidup penuh kesabaran atas situasi yang sedang terjadi, tetaplah harus yakin meski dalam keterbatasan kemampuan.

Teks Tabe aku, tabe aku Tai maring, maring tabe aku Teti nabe, nabe sera sorong Ke tai maring, maring tabe aku 'apa yang mesti kita keluhkan karena nasib hidup kita adalah penyelenggaraan-Nya' merupakan amanah untuk dipertanggungjawabkan oleh setiap individu karena teks tersebut mengacu pada prinsip hidup yang sungguh sederhana, tidak ada yang perlu dikhawatirkan, apalagi dikeluh-kesahkan, karena semua ini sudah dalam penyertaan sekaligus kehendak Tuhan.

Teks Aerunta Wulang haka lega lewo Mo kepae-kepae nenang goek Mo kepae-kepae nenang goek, nenang ake, akene lupa lela biarpun bulan berganti bulan, jangan kiranya kamu melupakan janji di antara kita berdua' merupakan sikap belajar untuk bertanggung jawab untuk tidak lupa apalagi melupakan. Bertanggung jawab untuk menghargai atas prinsip komitmen atau janji yang sudah disepakati bersama.

Dalam teks Watan haka-watan haka, lering dore dore watan haka Guti rata, rata taping tena, tena tueng, tueng balik hala 'berjalan menyusuri tepi pantai, sambil mendambakan engkau yang tak kunjung datang' mencerminkan sikap bertanggung jawab terhadap diri sendiri, yaitu sabar untuk berjalan menurut prinsip kehendak diri sambil tetap bertanggung jawab dan fokus sekalipun yang ditunggu belum kunjung tiba.

Kemudian prinsip kontekstualisasi dalam teks Kai Mura Le tampak pada penegasan bahwa kondisi budaya masyarakat secara langsung maupun tidak langsung, memberikan dorongan atau pengaruh bagi pengembangan epistemologi itu sendiri. Maksudnya, epistemologi menyatu dengan seluruh lapisan sosial dan tradisi kebudayaan itu sendiri. Hal tersebut merupakan pengejawantahan kesungguhan dari watak kebudayaan atau manusia yang berbudaya adalah kesungguhan atas pengetahuan itu sendiri, seperti tampak pada Teti tuwo buko lodo, tuwo pureko di kae nire, Lali wato tena bera, Maaro berara di kae nire 'jangan lagi disesali lagi karena semuanya telah terlambat, kamu telah telanjur melakukannya'. Kontekstualisasi atas teks memberikan keyakinan untuk berpegang teguh terhadap ajaran bagi kehidupan supaya lebih memilih untuk maju dalam pemikiran.

Tampak juga pada bunyi teks Etep teti belia lidang, cuma kabe, kabe lidang saja Cuma kabe, kabe lidang saja, lidang kete keteko di hala 'kuajak kamu marilah duduk 
berdampingan denganku, dengan berdampingan kamu takkan kubawa pergi'. Atas teks di atas tersirat juga tersurat agar dalam kehidupan ini agar yakin dalam menelurkan pemikiran dan gagasan bagi harapan hidup kemanusiaan yang tidak bisa dilepaskan dari cara tasiran antara manusia dan lingkungannya.

Teks Etep teti belia lidang, cuma kabe, kabe lidang saja cuma kabe, kabe lidang saja, lidang kete keteko di hala 'kuajak kamu marilah duduk berdampingan denganku, dengan berdampingan kamu takkan kubawa pergi' merupakan prinsip dasar masyarakat, dalam hal ini ialah Flores Timur, Adonara; senda gurau dalam percakapan sesusai pulang dari, seperti berkebun atau lainnya. aktivitas memberikan pengaruh kuat untuk diakhiri dengan duduk bersama-sama sembari menceritakan pengalaman masing-masing sebelum kembali melakukan kegiatan lain pada esok hari. Ajakan atas teks juga merupakan rangkulan berasaskan semangat kemanusiaan bahwa asalkan bersama, maka kebersamaan selalu dijunjung tinggi.

Teks Gampang hala, gampang hala ata ana, ana gampang hala ana weling, weling witi bala, ata ana, ana gampang hala. 'sungguh tidak mudah mengambil anak gadis itu, karena dia bermaharkan gading dan kambing, merupakan prinsip yang seara langsung memberikan informasi kebudayaan atas/masyarakat. Dalam hal ini, Dolo Kai Mera Le mengabarkan prinsip pemikiran adilhung ke dalam situasi sosial dan budaya dalam masyarakat.

\section{PENUTUP}

Proses pembelajaran pada akhirnya merupakan ilmu pengetahuan atas asumsi Revitalisasi Sastra di Adonara, Flores Timur. Hal tersebut dapat dikatakan juga sebagai pembelajaran sekaligus perekatan dalam lintas budaya, pantun dalam teks Kai Mura Le dalam tradisi lisan dolo memiliki keragaman tema yang berbeda. Tematis justru membuat judul menjadi berbeda, di Pulau Adonara di Flores Timur tradisi sole dengan semangat pantun yang menceritakan budi jasa nenek moyang dahulu kala, lalu oba dengan pantun yang cenderung sebuah cerita-cerita sedih masa lampau tentang kehidupan nenek moyang, sementara dapat disebut mencakup wilayah keseharian atas renik persoalan muda-mudi.

Selain itu, dengan memperhitungkan kekuatan teks Kai Mura Le, semangat epistemologi kian penting karena secara tersurat membiaskan persoalan humanitas yang tampak bagi prinsip kehidupan. Pengetahuan yang diumpamakan ke dalam amanat sekaligus amanah. Artinya, bila sudah disertakan/besertakan kejelasan tujuan, tidak perlu lagi dikendalikan oleh kebimbangan apalagi ketidakpastian.

Prinsip holistik dalam teks Kai Mura Le merupakan pengembangan epistemologi atas bangunan pengertian tentang kebenaran yang bersifat intersubjektif-bukan hanya bersifat mengalami, melainkan mengekspresikan pengalaman bagi dirinya sendiri. Sejatinya tidak dibenarkan memandang kehidupan ini dengan sikap setengah hati, tetapi harus penuh dalam kepercayaan diri.

Prinsip tanggung jawab dalam teks Kai Mura Le, menampilkan sikap yang selalu keharusan dari setiap permasalahan atas perkataan ataupun perbuatan dari seseorang. Secara langsung mengandung reduksi kedalaman humaniora yang tidak dangkal. Selain itu, Kai Mura Le tampak pada penegasan bahwa kondisi budaya masyarakat secara langsung maupun tidak langsung, memberikan dorongan atau pengaruh bagi pengembangan epistemologi itu sendiri. Maksudnya, epistemologi menyatu dengan seluruh lapisan sosial dan tradisi kebudayaan itu sendiri.

Kemudian prinsip kontekstualisasi atas teks Kai Mura Le memberikan keyakinan untuk berpegang teguh terhadap ajaran bagi kehidpan supaya lebih memilih 
untuk maju dalam pemikiran. Maka teks Kai Mura Le secara tersirat dan tersurat adalah sikap yakin dalam menelurkan pemikiran dan gagasan bagi harapan hidup kemanusiaan. Hal ini tidak bisa dilepaskan dari cara tafsiran manusia dan lingkungannya.

\section{DAFTAR PUSTAKA}

Klawes, David. (2019). Menelisik Dolo-Dolo. Adonara: Horinara.

Lawe, David Kopong. (2018). Draf Pemikiran sebagai Bahan Telaahan Bersama: Mengendus Identitas Adonara Lamabolot. Adonara: Horinara.

Purwaningsih, dkk. (2019). Kajian Vitalitas Sastra Lisan Dolo-Dolo Di Flores Timur, Nusa Tenggara Timur. Makalah Tidak Diterbitkan, ada pada penulis.

Revitalisasi (Def.1) (n.d). Dalam Kamus Besar Bahasa Indonesia (KBBI) daring. Diakses melalui https://kbbi.kemdikbud.go.id/entri/revitalisasi, 10 Maret 2020.

Suriasumantri, Jujun S. (1990). Filsafat Ilmu Sebuah Pengantar Populer. Jakarta: Pustaka Sinar Harapan.

Sudarminta, J. (2002). Epistemologi Dasar: Pengetahuan filsafat Ilmu Pengetabuan. Jakarta: Kanisius.

Uhi, Jannes Alexander. (2016). Filsafat Kebudayaan: Konstruksi Pemikiran Anthonie Van Peursen dan Catatan Reflektifnya. Yogyakarta: Pustaka Pelajar.

Uhi, Jannes Alexander. (2018). Pengembangan Epistemologi Realisme melalui Prinsip-prinsip Kultural. Makalah Tidak Diterbitkan, ada pada Penulis.

Watloly, Aholiab. (2001). Tanggung Jawab Pengetahuan: Mempertimbangkan Epistemologi secara Kultural. Yogyakarta: Kanisius.

Narasumber: David Klawes (63), Bernard Tukan (63), Silverster Hurit, Pater Erich (26), Ama Berry (42) 